\title{
Importance of hematological parameters for micro- and macrovascular outcomes in patients with type 2 diabetes: the Rio de Janeiro type 2 diabetes cohort study
}

\author{
Claudia R. L. Cardoso* ${ }^{*}$, Nathalie C. Leite and Gil F. Salles
}

\begin{abstract}
Background: The prognostic importance of several hematological parameters has been scarcely investigated in type 2 diabetes. So, we aimed to evaluate their prognostic importance for development of complications in a cohort of type 2 diabetes.

Methods: In a prospective study, 689 individuals with type 2 diabetes had blood red cell, platelet and leukocyte parameters obtained at baseline. Multivariate Cox analyses examined the associations between several hematological parameters (including neutrophyl-to-lymphocyte, lymphocyte-to-monocyte, platelet-to-lymphocyte, and monocyteto-HDL ratios) and the occurrence of microvascular (retina, renal and peripheral neuropathy) and cardiovascular complications (total cardiovascular events [CVEs], and major adverse CVEs [MACEs]), and all-cause and cardiovascular mortality. Improvements in risk discrimination were assessed by C-statistics and Integrated Discrimination Improvement (IDI) index.
\end{abstract}

Results: During a median follow-up of 10.5 years, 212 patients had a CVE (174 MACEs), 264 patients died (131 cardiovascular deaths); 206 had a renal, 161 a retinopathy and 179 patients had a neuropathy outcome. In multivariateadjusted analyses, the lymphocytes count and lymphocyte-to-monocyte ratio were protective (hazard ratios [HRs]: 0.77 and 0.72 , respectively), whereas the neutrophyl-to-lymphocyte and platelet-to-lymphocyte ratios were associated with increased risks (HRs: 1.19 and 1.17) for all-cause mortality. For cardiovascular mortality, the monocytes count, the neutrophyl-to-lymphocyte and monocyte-to-HDL ratios were associated with increased risks and the lymphocyte-to-monocyte ratio was protective. Higher lymphocyte-to-monocyte ratio was protective for renal failure outcome. However, none of them improved risk discrimination.

Conclusions: Low lymphocytes count and leukocyte ratios that mainly included lymphocytes were predictors of macrovascular complications and mortality in individuals with type 2 diabetes. However, they did not improve risk prediction over traditional risk factors.

Keywords: Hematologic parameters, Cardiovascular outcomes, Cohort study, Microvascular complications, Mortality, Type 2 diabetes

*Correspondence: claudiacardoso@hucff.ufrj.br

Department of Internal Medicine, University Hospital Clementino Fraga Filho, School of Medicine; Universidade Federal Do Rio de Janeiro, Rua

Croton, 72, Rio de Janeiro, Jacarepagua 22750-240, Brazil

\section{Background}

Type 2 diabetes is a major health problem worldwide. The chronic micro- and macrovascular complications that increase with diabetes severity and duration are

c) The Author(s) 2021. This article is licensed under a Creative Commons Attribution 4.0 International License, which permits use, sharing, adaptation, distribution and reproduction in any medium or format, as long as you give appropriate credit to the original author(s) and the source, provide a link to the Creative Commons licence, and indicate if changes were made. The images or other third party material in this article are included in the article's Creative Commons licence, unless indicated otherwise in a credit line to the material. If material is not included in the article's Creative Commons licence and your intended use is not permitted by statutory regulation or exceeds the permitted use, you will need to obtain permission directly from the copyright holder. To view a copy of this licence, visit http://creativeco mmons.org/licenses/by/4.0/. The Creative Commons Public Domain Dedication waiver (http://creativecommons.org/publicdomain/ zero/1.0/) applies to the data made available in this article, unless otherwise stated in a credit line to the data. 
responsible for a great burden of disease-related morbidity and mortality. Systemic low-grade chronic inflammation has long been recognized as a central biological mainstay of diabetes and growing evidences suggest that inflammation plays an important role in diabetes-related complications [1, 2]. Indeed, atherosclerosis, which underlies the macrovascular complications, is currently regarded as a chronic inflammatory disease [1]. Inflammatory cells contribute to atherosclerotic lesion initiation, progression and its disruption that cause cardiovascular events [3]. Further, there are also evidences that inflammation may play a key role in occurrence of microvascular complications $[2,4-8]$.

In special, blood leukocytes are important in the course of vascular wall deterioration in individuals with diabetes, being involved in the progression of atherosclerosis and in destabilization and disrupt of plaque, culminating in atherothrombotic events $[9,10]$. Increasing concern has been demanded to leukocytes subtypes and its relations. Indeed, the neutrophyl-to-lymphocyte and the lymphocyte-to-monocyte ratios, and additionally other relations such as the platelet-to-lymphocyte, monocyte-to-HDL-cholesterol and also other hematological parameters such as the red blood cell distribution width (RDW), have been investigated as potential risk markers in several clinical conditions [3, 6-8, 11-19]. These are inexpensive and easily-obtained measures to investigate inflammatory parameters and potential risk markers. The neutrophyl-to-lymphocyte ratio (NLR) is the most widely investigated and links two different pathways that initiate the inflammatory response. Neutrophyls are intimately associated with proceeding inflammation and lymphocytes reflect the immune regulatory response pathway $[20,21]$.

Several studies investigated the relationships between hematological parameters and the presence of degenerative complications in type 2 diabetes $[3,6-8,11,13-15$, 17, 18], but few explored their prognostic importance for adverse outcomes in longitudinal analyses [11, 22, 23]. Otherwise, these previous studies were mainly retrospective [11,22] and focused on specific hematological parameters, such as the NLR $[11,22]$ and monocytes count [23], and in specific outcomes, such as cardiovascular events [11], renal function deterioration [22] and all-cause mortality [23]. The prognostic importance of other hematological parameters, such as the lymphocyte-to-monocyte, platelet-to-lymphocyte, or monocyte-to-HDL ratios, has never been investigated in type 2 diabetes; only simple associations were examined in cross-sectional analyses [6, 15, 17, 18, 24]. Moreover, none of the previous longitudinal studies [11, 22, 23] evaluated whether any of the hematological parameters was able to improve risk discrimination for the specific analyzed outcome. Hence, a comprehensive longitudinal analysis on the prognostic importance of several hematological parameters for macro- and microvascular complications outcomes in diabetes has never been performed yet, and it is needed.

Therefore, we intended to investigate in a prospective cohort of middle-aged type 2 diabetic individuals the prognostic value of several hematological parameters for future occurrence of macro- and microvascular complications and mortality, and to explore if they improve risk discrimination over and beyond traditional risk markers.

\section{Methods}

\section{Patients and baseline procedures}

This prospective study included 689 individuals with type 2 diabetes from the Rio de Janeiro Type 2 Diabetes (RIOT2D) Cohort Study, enrolled between August 2004 and December 2008 and followed-up until June 2019 in the diabetes outpatient clinic of our tertiary-care University Hospital. All participants gave written informed consent, and the local Ethics Committee had previously approved the study protocol. The characteristics of this cohort, the baseline procedures and the diagnostic definitions have been described previously [25-29]. In summary, inclusion criteria were all adult type 2 diabetic individual up to 80 years old with either any microvascular (retinopathy, nephropathy or neuropathy) or macrovascular (coronary, cerebrovascular or peripheral artery disease) complication, or with at least two other modifiable cardiovascular risk factors. Exclusion criteria were morbid obesity (body mass index $\geq 40 \mathrm{~kg} / \mathrm{m}^{2}$ ), advanced renal failure (serum creatinine $>180 \mu \mathrm{mol} / \mathrm{L}$ or estimated glomerular filtration rate $<30 \mathrm{ml} / \mathrm{min} / 1.73 \mathrm{~m}^{2}$ ) or the presence of any serious concomitant disease limiting life expectancy. All participants were submitted to a standard baseline protocol that included a thorough clinical-laboratory evaluation. Diagnostic criteria for diabetic chronic complications were detailed previously [25-29]. In brief, coronary heart disease was diagnosed by clinical, electrocardiographic criteria, or by positive ischemic stress tests. Cerebrovascular disease was diagnosed by history and physical examination, and peripheral arterial disease by an anklebrachial index $<0.9$. The diagnosis of nephropathy needed at least two albuminurias $\geq 30 \mathrm{mg} / 24 \mathrm{~h}$ or proteinurias $\geq 0.5 \mathrm{~g} / 24 \mathrm{~h}$ or confirmed reduction of glomerular filtration rate (eGFR $\leq 60 \mathrm{ml} / \mathrm{min} / 1.73 \mathrm{~m}^{2}$, estimated by the CKD-EPI equation, or serum creatinine $>130 \mu \mathrm{mol} / \mathrm{L}$ ). Peripheral neuropathy was determined by clinical examination (knee and ankle reflex activities, feet sensation with the Semmes-Weinstein monofilament, vibration with a $128-\mathrm{Hz}$ tuning fork, pinprick and temperature sensations) and neuropathic symptoms were assessed by a standard validated questionnaire [27]. Clinic blood 
Table 1 Characteristics of all diabetic patients and divided into tertiles of the neutrophyl-to-lymphocyte ratio

\begin{tabular}{|c|c|c|c|c|}
\hline Characteristics & $\begin{array}{l}\text { All patients } \\
(n=689)\end{array}$ & $\begin{array}{l}\text { 1st tertile } \\
<1.6 \\
(n=229)\end{array}$ & $\begin{array}{l}\text { 2nd tertile } \\
\geq 1.6 \text { to }<2.2 \\
(\mathrm{n}=230)\end{array}$ & $\begin{array}{l}\text { 3rd tertile } \\
\geq 2.2 \\
(\mathrm{n}=230)\end{array}$ \\
\hline Age (years) & $60.0(9.6)$ & $60.0(9.4)$ & $59.0(9.4)$ & $61.0(9.8)$ \\
\hline Male sex (\%) & 39.2 & 34.5 & 37.8 & 45.2 \\
\hline $\mathrm{BMI}\left(\mathrm{kg} / \mathrm{m}^{2}\right)$ & $29.7(4.8)$ & $30.1(4.8)$ & $30.1(4.9)$ & 29.0 (4.8)‡ \\
\hline Smoking, current/past (\%) & 45.1 & 43.2 & 39.7 & $52.2 \neq$ \\
\hline Physical activity (\%) & 22.2 & 24.0 & 19.2 & 23.5 \\
\hline Diabetes duration (years) & $8(3-15)$ & $7(3-14)$ & $7(3-14.5)$ & $9(4-17)$ \\
\hline \multicolumn{5}{|l|}{ Chronic diabetic complications (\%) } \\
\hline Cerebrovascular disease & 9.2 & 8.7 & 11.4 & 7.4 \\
\hline Coronary artery disease & 15.1 & 14.8 & 11.8 & 18.7 \\
\hline Peripheral artery disease & 16.9 & 16.6 & 14.0 & 20.1 \\
\hline Retinopathy & 32.3 & 31.8 & 31.5 & 33.6 \\
\hline Nephropathy & 31.6 & 28.1 & 29.3 & 37.4 \\
\hline Peripheral neuropathy & 29.1 & 30.1 & 25.1 & 31.9 \\
\hline Cardiovascular autonomic neuropathy & 24.7 & 20.6 & 26.5 & 27.0 \\
\hline \multicolumn{5}{|l|}{ Diabetes treatment (\%) } \\
\hline Metformin & 87.9 & 88.2 & 88.6 & 87.0 \\
\hline Sulfonylureas & 43.0 & 40.6 & 45.0 & 43.5 \\
\hline Insulin & 48.1 & 48.0 & 48.9 & 47.4 \\
\hline Aspirin & 89.6 & 88.2 & 88.3 & 92.2 \\
\hline Dyslipidemia (\%) & 87.1 & 86.5 & 86.0 & 88.7 \\
\hline Statins use (\%) & 77.0 & 75.0 & 73.4 & $82.5 \neq$ \\
\hline Arterial hypertension (\%) & 86.6 & 86.5 & 86.0 & 88.7 \\
\hline Number of anti-hypertensive drugs & $3(1-3)$ & $3(1-3)$ & $2(1-3)$ & $3(2-4)$ \\
\hline \multicolumn{5}{|l|}{ Blood pressures $(\mathrm{mmHg})$} \\
\hline Mean clinic SBP & $140(19)$ & $140(19)$ & $140(20)$ & $141(19)$ \\
\hline Mean clinic DBP & $79(11)$ & $79(11)$ & $80(11)$ & $79(10)$ \\
\hline \multicolumn{5}{|l|}{ Hematological parameters } \\
\hline Haemoglobin (g/dl) & $13.7(1.5)$ & $13.6(1.5)$ & $13.7(1.5)$ & $13.6(1.6)$ \\
\hline RDW (\%) & $13.1(1.3)$ & $13.0(1.5)$ & $13.0(1.3)$ & $13.2(1.4)$ \\
\hline Leukocytes $\left(\times 10^{3}\right.$ cells $\left./ \mathrm{mm}^{3}\right)$ & $7.4(2.1)$ & $6.7(2.0)$ & $7.3(2.0) \dagger$ & $8.1(2.1)^{*}$ \\
\hline Neutrophyls $\left(\times 10^{3}\right.$ cells $\left./ \mathrm{mm}^{3}\right)$ & $4.3(1.6)$ & $3.2(1.1)$ & $4.2(1.1)^{*}$ & $5.4(1.6)^{*}$ \\
\hline Lymphocytes $\left(\times 10^{3}\right.$ cells $\left./ \mathrm{mm}^{3}\right)$ & $2.2(0.8)$ & $2.7(0.9)$ & $2.3(0.7)^{*}$ & $1.8(0.5)^{*}$ \\
\hline Monocytes (cells/mm³) & $500(185)$ & $473(183)$ & $497(171)$ & $528(197) \dagger$ \\
\hline Platelets $\left(\times 10^{3}\right.$ cells $\left./ \mathrm{mm}^{3}\right)$ & $244(74)$ & $250(83)$ & $243(65)$ & $241(74)$ \\
\hline Lymphocyte-to-monocyte ratio & $5.0(2.4)$ & $6.4(2.8)$ & $4.9(1.7)^{*}$ & $3.8(1.8)^{*}$ \\
\hline Platelet-to-lymphocyte ratio & $118.2(46.3)$ & $98.4(35.8)$ & $113.5(35.7)^{*}$ & $142.6(52.4)^{*}$ \\
\hline Monocyte-to-HDL ratio & $12.7(6.3)$ & $12.0(5.9)$ & $12.7(6.5)$ & $13.3(6.5)$ \\
\hline \multicolumn{5}{|l|}{ Laboratory variables } \\
\hline Mean $\mathrm{HbA}_{1 c}(\%)$ & $7.7(1.6)$ & $7.7(1.6)$ & $7.6(1.5)$ & $7.7(1.6)$ \\
\hline$(\mathrm{mmol} / \mathrm{mol})$ & $61(11.6)$ & $61(11.6)$ & $60(10.5)$ & $61(11.6)$ \\
\hline Mean triacylglycerol (mmol/L) & $1.55(1.08-2.22)$ & $1.60(1.14-2.29)$ & $1.59(1.12-2.30)$ & $1.43(1.00-2.07)$ \\
\hline Mean HDL-cholesterol (mmol/L) & $1.14(0.44)$ & $1.14(0.28)$ & $1.11(0.28)$ & $1.16(0.65)$ \\
\hline Mean LDL-cholesterol (mmol/L) & $2.77(0.85)$ & $2.84(0.83)$ & $2.79(0.88)$ & $2.74(0.85)$ \\
\hline C-reactive protein (CRP) mg/L & $2.9(1.2-6.2)$ & $2.7(0.9-6.1)$ & $3.1(1.5-6.3)$ & $2.8(1.3-6.5)$ \\
\hline Glomerular filtration rate $\left(\mathrm{ml} / \mathrm{min} / 1.73 \mathrm{~m}^{2}\right)$ & $81(20)$ & $82(19)$ & $83(21)$ & $79(21)$ \\
\hline Albuminuria (mg/24 h) & $13(7-41)$ & $14(7-32)$ & $13(7-39)$ & $15(7-52)$ \\
\hline \multicolumn{5}{|l|}{ Macrovascular outcomes ${ }^{\mathrm{a}}$} \\
\hline Total CV events & $212(35.2)$ & $62(29.9)$ & $61(29.9)$ & $89(46.7) \dagger$ \\
\hline
\end{tabular}


Table 1 (continued)

\begin{tabular}{|c|c|c|c|c|}
\hline Characteristics & $\begin{array}{l}\text { All patients } \\
(n=689)\end{array}$ & $\begin{array}{l}\text { 1st tertile } \\
<1.6 \\
(n=229)\end{array}$ & $\begin{array}{l}\text { 2nd tertile } \\
\geq 1.6 \text { to }<2.2 \\
(n=230)\end{array}$ & $\begin{array}{l}\text { 3rd tertile } \\
\geq 2.2 \\
(n=230)\end{array}$ \\
\hline Major CV events & $174(27.8)$ & $56(26.5)$ & $45(21.2)$ & $73(36.3)+$ \\
\hline Cardiovascular mortality & $131(20.1)$ & $44(19.9)$ & 30 (13.6) & $57(27.3)+$ \\
\hline All-cause mortality & $264(40.5)$ & $80(36.2)$ & $78(35.2)$ & $106(50.7) \dagger$ \\
\hline \multicolumn{5}{|l|}{ Microvascular outcomes ${ }^{b}$} \\
\hline Retinopathy (incident/worsening) $(n=551)$ & $161(50.7)$ & $51(49.5)$ & $56(53.2)$ & $54(49.4)$ \\
\hline Renal composite & $206(37.7)$ & $67(36.1)$ & $63(33.3)$ & $76(44.4)$ \\
\hline Microalbuminuria (incident) & $127(25.6)$ & $43(25.4)$ & $35(20.4)$ & $49(31.4)$ \\
\hline Renal failure & $104(17.0)$ & $29(14.0)$ & $34(16.4)$ & $41(21.0)$ \\
\hline Peripheral neuropathy (incident/worsening) $(n=525)$ & $179(34.1 \%)$ & $51(28.5 \%)$ & $65(36.9 \%)$ & $63(37.1 \%)$ \\
\hline
\end{tabular}

Values are proportions, and means (standard deviations) or medians (interquartile range). $B M I$ body mass index, $S B P$ systolic blood pressure, $D B P$ diastolic blood pressure, $R D W$ red cell distribution width, $H D L$ high-density lipoprotein, $L D L$ low-density lipoprotein, $H b A_{1 c}$ glycated hemoglobin, $C V$ cardiovascular

${ }^{\text {a }}$ Values are absolute numbers (incidence rate per 1000 patient-years of follow-up)

${ }^{b}$ Values are absolute numbers (incidence rate per 1000 patient-years of follow-up), except for peripheral neuropathy that are absolute numbers (proportions)

$\neq \mathrm{p}<0.05 ; \mathrm{tp}<0.01$; $\mathrm{p}<0.001$ (after Bonferroni's correction) for comparisons with the reference 1st tertile subgroup

pressure (BP) was measured three times using a digital oscillometric BP monitor (HEM-907XL, Omron Healthcare, Kyoto, Japan) with a suitable sized cuff on two occasions two weeks apart at study entry [25]. The first measure of each visit was discarded and BP considered was the mean between the last two readings of each visit. Arterial hypertension was diagnosed if mean systolic $(\mathrm{SBP}) \geq 140 \mathrm{mmHg}$ or diastolic BP $(\mathrm{DBP}) \geq 90 \mathrm{mmHg}$ or if anti-hypertensive drugs had been prescribed. Laboratory evaluation included hemogram, fasting glycemia, glycated hemoglobin $\left(\mathrm{HbA}_{1 \mathrm{c}}\right)$, serum creatinine and lipids. Albuminuria and proteinuria were evaluated in two non-consecutive sterile 24-h urine collections.

\section{Assessment of hematological parameters}

Fasting blood samples were collected for performing all laboratory exams in the Central Laboratory of our University Hospital. A complete blood count was performed with an automated hematology analyzer (Coulter LH-750 Analyzer, Beckman Coulter, USA), and it included hemoglobin concentration and red blood cell distribution width (RDW), total leukocytes, neutrophyls, lymphocytes, monocytes and platelets counts. The neutrophyl-to-lymphocyte, lymphocyte-to-monocyte, platelet-to-lymphocyte and monocyte-to-HDL ratios were calculated using the complete blood count measures. No participant had any signs or symptoms of any acute clinical condition, including bacterial or viral infections, prior to blood sampling. All individuals who had abnormally low or high leucocytes count had their exam repeated after a month to confirm the results; if they were discordant, it was considered the one with normal values, and if they were concordant, it was considered the first collected.

\section{Follow-up and outcomes assessment}

The patients were followed-up regularly at least 3-4 times a year until June 2019 under standardized treatment. The observation period for each patient was the number of months from the date of the first clinical examination to the date of the last clinical visit until June 2019 or the date of the first endpoint, whichever came first. The primary outcomes were the occurrence of any macrovascular or microvascular events. Macrovascular outcomes were total cardiovascular events (CVEs: fatal or non-fatal myocardial infarctions [MIs], sudden cardiac deaths, new-onset heart failure, death from progressive heart failure, any myocardial revascularization procedure, fatal or non-fatal strokes, any aortic or lower limb revascularization procedure, any amputation above the ankle, and deaths from aortic or peripheral arterial disease), major adverse cardiovascular events (MACEs: non-fatal MIs and strokes plus cardiovascular deaths), and all-cause and cardiovascular mortalities [25, 26]. Microvascular outcomes were retinopathy development or worsening [28], renal outcomes [29] (new microalbuminuria development, and renal function deterioration [defined as doubling of serum creatinine or end-stage renal failure needing dialysis or death from renal failure], and a composite of them), and peripheral neuropathy development or worsening [27]. Retinopathy and renal outcomes were evaluated by annual examinations [28, 29], whereas peripheral neuropathy was evaluated on two serial specific examinations performed after a median of 6 and 10 years from the baseline examination $[27,30]$. 
a All-cause mortality

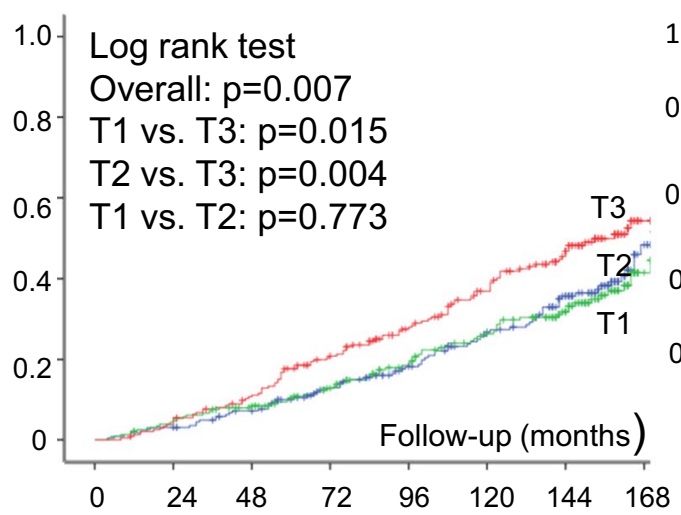

Number of patients at risk:

$\begin{array}{llllllll}\text { A: } 228 & 216 & 200 & 173 & 148 & 123 & 90 & 20 \\ \text { B: } 228 & 213 & 198 & 175 & 150 & 128 & 96 & 19 \\ \text { C: } 228 & 224 & 204 & 174 & 142 & 115 & 80 & 16\end{array}$

C: $228 \quad 224 \quad 204 \quad 174 \quad 142 \quad 115 \quad 80 \quad 16$

\section{b Cardiovascular mortality}

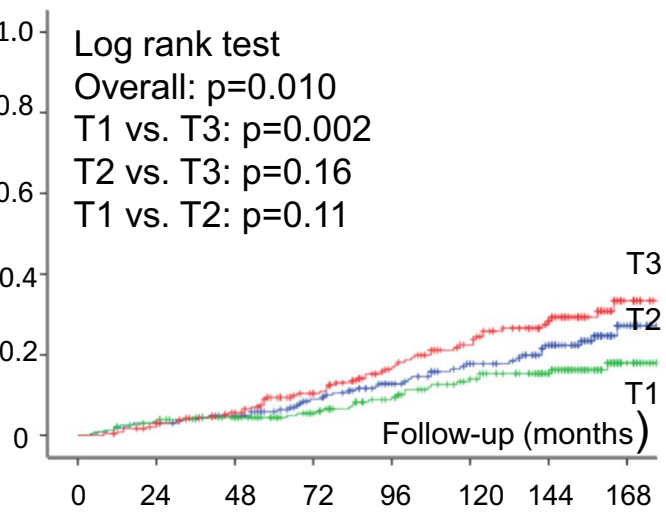

Number of patients at risk:

$\begin{array}{llllllll}\text { A: } 228 & 216 & 200 & 173 & 148 & 123 & 90 & 20 \\ \text { B: } 226 & 213 & 198 & 175 & 150 & 128 & 96 & 19 \\ \text { C: } 228 & 224 & 204 & 174 & 142 & 115 & 80 & 16\end{array}$

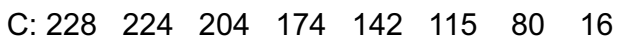

c Major cardiovascular events

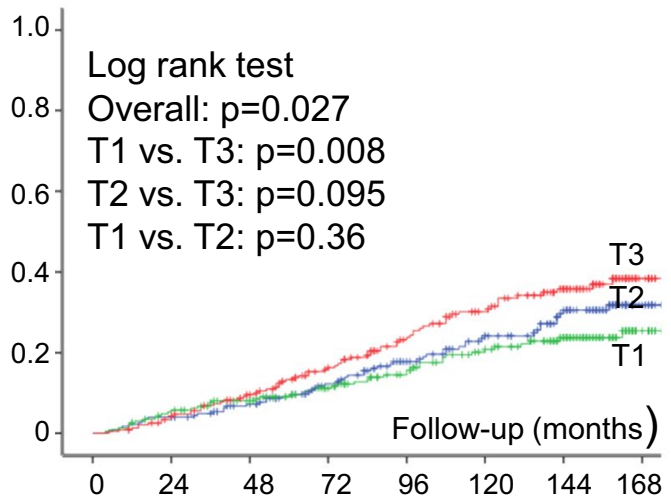

Number of patients at risk:

$\begin{array}{lllllllll}\text { A: } & 228 & 214 & 195 & 165 & 138 & 113 & 79 & 17 \\ \text { B: } & 228 & 209 & 191 & 166 & 142 & 119 & 87 & 17 \\ \text { C: } & 228 & 220 & 198 & 166 & 134 & 107 & 74 & 16\end{array}$

\section{d Total cardiovascular events}

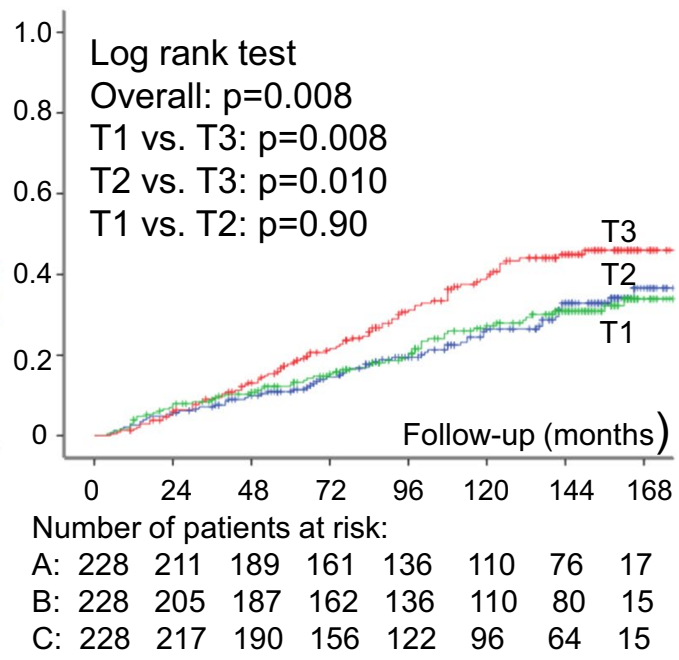

Fig. 1 Kaplan-Meier estimation curves of cumulative incidences of adverse outcomes all-cause mortality (a); cardiovascular mortality (b); major adverse cardiovascular events (c); and total cardiovascular events (d), for patients divided into tertiles (T1, lowest; T2, middle; T3 highest) of the neutrophyl-to-lymphocyte ratio

\section{Statistical analyses}

Continuous data were described as means (SD) or as medians (interquartile range). For initial exploratory analyses, patients were categorized into tertiles of the NLR (because this is the most widely-used ratio) and baseline characteristics compared by ANOVA, Kruskal-Wallis or $\chi^{2}$ tests, when appropriate. Kaplan-Meier curves of cumulative endpoints incidence during follow-up, compared by log-rank tests, were used for assessing different incidences of outcomes among tertile subgroups. For assessing the prognostic value for each macrovascular and microvascular outcome, except for peripheral neuropathy, a time-to-event Cox analysis was undertaken with progressively increasing statistical adjustments for potential confounding. Model 1 was only adjusted for age and sex; and Model 2 was further adjusted for other potential confounders (diabetes duration, body mass index $[\mathrm{BMI}]$, smoking status, physical inactivity, office SBP, number of anti-hypertensive drugs in use, presence of micro- and macrovascular complications at baseline, 
Table 2 Results of Cox survival analyses for the excess risks associated with continuous hematological parameters (increments of 1-SD) for the occurrence of future cardiovascular complications and all-cause mortality

\begin{tabular}{|c|c|c|c|c|}
\hline $\begin{array}{l}\text { Outcomes } \\
\text { Hematological parameters }\end{array}$ & $\begin{array}{l}\text { Model } 1 \\
\text { HR }(95 \% \mathrm{Cl})\end{array}$ & $\begin{array}{l}\text { Model } 2 \\
\text { HR }(95 \% \mathrm{Cl})\end{array}$ & $\begin{array}{l}\text { C-statistic } \\
\text { (AUC) }\end{array}$ & $\begin{array}{l}\text { Relative IDI } \\
(\%)\end{array}$ \\
\hline \multicolumn{5}{|l|}{ Total CV events $(n=212)$} \\
\hline Haemoglobin & $0.93(0.80-1.08)$ & $0.98(0.84-1.14)$ & - & - \\
\hline RDW & $1.04(0.91-1.19)$ & $1.05(0.92-1.21)$ & - & - \\
\hline Leukocytes & $1.19(1.04-1.37) \ddagger$ & $1.07(0.93-1.24)$ & - & - \\
\hline Neutrophyls & $1.19(1.04-1.36) \neq$ & $1.10(0.96-1.26)$ & - & - \\
\hline Lymphocytes & $0.99(0.84-1.17)$ & $0.96(0.80-1.14)$ & - & - \\
\hline Monocytes & $1.18(1.04-1.35) \neq$ & $1.10(0.95-1.26)$ & - & - \\
\hline Platelets & $1.14(0.99-1.31)$ & $1.11(0.96-1.29)$ & - & - \\
\hline Neutrophyl-to-lymphocyte ratio & $1.15(1.02-1.30) \neq$ & $1.10(0.97-1.24)$ & - & - \\
\hline Lymphocyte-to-monocyte ratio & $0.85(0.72-1.01)$ & $0.89(0.75-1.05)$ & - & - \\
\hline Platelet-to-lymphocyte ratio & $1.07(0.94-1.23)$ & $1.08(0.94-1.25)$ & - & - \\
\hline Monocyte-to-HDL ratio & $1.20(1.05-1.37) \dagger$ & $1.09(0.94-1.26)$ & - & - \\
\hline \multicolumn{5}{|l|}{ Major CV events $(n=174)$} \\
\hline Haemoglobin & $0.92(0.78-1.08)$ & $0.93(0.79-1.10)$ & - & - \\
\hline RDW & $1.05(0.91-1.21)$ & $1.06(0.92-1.23)$ & - & - \\
\hline Leukocytes & $1.19(1.02-1.38) \neq$ & $1.07(0.92-1.25)$ & - & - \\
\hline Neutrophyls & $1.18(1.02-1.37) \neq$ & $1.10(0.96-1.27)$ & - & - \\
\hline Lymphocytes & $0.96(0.80-1.15)$ & $0.92(0.76-1.11)$ & - & - \\
\hline Monocytes & $1.20(1.04-1.38) \neq$ & $1.10(0.94-1.27)$ & - & - \\
\hline Platelets & $1.13(0.98-1.31)$ & $1.12(0.97-1.29)$ & - & - \\
\hline Neutrophyl-to-lymphocyte ratio & $1.17(1.03-1.33) \neq$ & $1.13(0.99-1.29)$ & - & - \\
\hline Lymphocyte-to-monocyte ratio & $0.86(0.71-1.03)$ & $0.90(0.75-1.09)$ & - & - \\
\hline Platelet-to-lymphocyte ratio & $1.07(0.93-1.25)$ & $1.10(0.94-1.28)$ & - & - \\
\hline Monocyte-to-HDL ratio & $1.24(1.07-1.43) \dagger$ & $1.12(0.96-1.31)$ & - & - \\
\hline CV mortality $(n=131)$ & & & $0.716(0.668-0.765)$ & \\
\hline Haemoglobin & $0.93(0.76-1.12)$ & $0.95(0.78-1.16)$ & - & - \\
\hline RDW & $1.15(0.98-1.34)$ & $1.17(0.99-1.38)$ & - & - \\
\hline Leukocytes & $1.19(0.99-1.41)$ & $1.10(0.91-1.32)$ & - & - \\
\hline Neutrophyls & $1.21(1.03-1.44) \neq$ & $1.15(0.97-1.36)$ & - & - \\
\hline Lymphocytes & $0.87(0.70-1.08)$ & $0.81(0.64-1.02)$ & - & - \\
\hline Monocytes & $1.27(1.08-1.50) \dagger$ & $1.20(1.01-1.44) \neq$ & $0.724 \S$ & $15.5 \% \S$ \\
\hline Platelets & $1.04(0.87-1.25)$ & $1.02(0.85-1.22)$ & - & - \\
\hline Neutrophyl-to-lymphocyte ratio & $1.25(1.08-1.44) \dagger$ & $1.23(1.06-1.43) \dagger$ & $0.719 \S$ & $9.3 \% \S$ \\
\hline Lymphocyte-to-monocyte ratio & $0.72(0.57-0.92) \dagger$ & $0.74(0.58-0.95) \neq$ & $0.725 \S$ & $13.4 \% \S$ \\
\hline Platelet-to-lymphocyte ratio & $1.08(0.91-1.29)$ & $1.11(0.93-1.33)$ & - & - \\
\hline Monocyte-to-HDL ratio & $1.32(1.12-1.56)^{*}$ & $1.21(1.01-1.46) \neq$ & $0.722 \S$ & $15.5 \% \S$ \\
\hline All-cause mortality $(n=264)$ & & & $0.755(0.717-0.793)$ & \\
\hline Haemoglobin & $0.86(0.75-0.98)$ & $0.90(0.78-1.03)$ & - & - \\
\hline RDW & $1.08(0.96-1.21)$ & $1.08(0.96-1.22)$ & - & - \\
\hline Leukocytes & $1.10(0.97-1.25)$ & $1.04(0.91-1.18)$ & - & - \\
\hline Neutrophyls & $1.16(1.03-1.31) \neq$ & $1.11(0.98-1.25)$ & - & - \\
\hline Lymphocytes & $0.80(0.68-0.94) \dagger$ & $0.77(0.65-0.90) \dagger$ & $0.756 \S$ & $1.6 \% \S$ \\
\hline Monocytes & $1.20(1.07-1.35) \dagger$ & $1.13(0.99-1.28)$ & - & - \\
\hline Platelets & $1.04(0.91-1.18)$ & $1.02(0.89-1.16)$ & - & - \\
\hline Neutrophyl-to-lymphocyte ratio & $1.23(1.11-1.37)^{*}$ & $1.19(1.07-1.33)^{*}$ & $0.757 \S$ & $2.6 \% \S$ \\
\hline Lymphocyte-to-monocyte ratio & $0.69(0.58-0.82)^{*}$ & $0.72(0.60-0.86)^{*}$ & $0.763 \S$ & $9.5 \% \S$ \\
\hline Platelet-to-lymphocyte ratio & $1.17(1.04-1.31) \neq$ & $1.17(1.03-1.31) \neq$ & $0.756 \S$ & $0.5 \% \S$ \\
\hline Monocyte-to-HDL ratio & $1.21(1.07-1.37) \dagger$ & $1.11(0.97-1.27)$ & - & - \\
\hline
\end{tabular}


Table 2 (continued)

\begin{abstract}
Values are hazard ratios and $95 \%$ confidence intervals estimated for a 1-SD increment in each hematological parameter; $; p<0.001 ; \uparrow p<0.01 ; \neq p<0.05$. The SDs of the hematological parameters are shown on Table 1

Model 1 was adjusted for age and sex

Model 2 was adjusted for age, sex, diabetes duration, BMI, smoking, physical activity, office systolic BP, number and classes of anti-hypertensive drugs in use, presence of micro- and macrovascular complications at baseline, baseline $\mathrm{HbA}_{1 c}$ and LDL-cholesterol, and use of insulin, statins and aspirin

$H R$ hazard ratio, $C I$ confidence interval, $A U C$ area under curve, IDI integrated discrimination improvement, $C V$ cardiovascular, $R D W$ red cell distribution width, $S D$ standard deviation

${ }^{a} \mathrm{C}$-statistics and relative IDIs were calculated only in case the parameter was significantly associated with the outcome in Model 2, which was the reference model without the hematological parameter. $§$ None of the C-statistics were significantly higher than that of the baseline model, as well as no relative IDI was statistically significant
\end{abstract}

baseline $\mathrm{HbA}_{1 \mathrm{c}}$, HDL- and LDL-cholesterol levels, and use of insulin, statins and aspirin). These results were presented as hazard ratios (HRs) with their 95\% confidence intervals (CIs). For peripheral neuropathy analyses, a multiple logistic regression was used with the same progressively increasing statistical adjustments, except that height (instead of BMI) and the time-interval between the baseline and the other 2 neuropathy evaluations were included as adjusting covariates. These results were reported as odds ratios (ORs) with their respective 95\% CIs. Hematological parameters were examined both as continuous variables, with HRs and ORs estimated for increments of 1-SD to allow comparisons among them; and also categorized into tertiles, with HRs and ORs estimated for the highest tertile subgroup in relation to the reference lowest tertile subgroup. If any of the hematological parameters was demonstrated to be a significant predictor of any of the outcomes, then the improvement in risk discrimination of adding this parameter over a standard risk factor model (composed by those covariates in Model 2) for this specific outcome was tested by the C-statistic (analogous to the area under ROC curve applied to time-to-event analysis), compared by the method proposed by DeLong [31], and by the Integrated Discrimination Improvement (IDI) index [32, 33]. The IDI is equivalent to the difference in discrimination slopes between models with and without the new variable and its calculation is based on continuous differences in predicted risk in new and old models in individual cases (with outcome) and controls (without outcome). Both the absolute and the relative IDIs were calculated. The relative IDI, reported as a percentage, facilitates the IDI clinical interpretation, and is defined as the increase in the discrimination slope divided by the slope of the standard risk model [32, 33]. All statistics were performed with SPSS version 19.0 (SPSS Inc, Chicago, IL, USA) and R version 3.4.1 ( $\mathrm{R}$ Foundation for Statistical Computing, Vienna, Austria); and a 2-tailed probability value $<0.05$ was considered significant.

\section{Results}

Table 1 outlines the baseline characteristics of all the 689 patients included in the study and of those divided into tertiles of NLR. Individuals with higher NLR were leaner, and more frequently smokers than those with lower ratios. Expectedly, they had higher leukocyte and neutrophyl counts and lower lymphocytes than those with lower ratios. They also had higher monocyte counts and higher platelet-to-lymphocyte and lower lymphocyte-to-monocyte ratios. There were no differences in the prevalences of macro- or microvascular complications at baseline, as well as in metabolic and BP control.

\section{Endpoints incidence during follow-up}

Over a median follow-up of 10.5 years (IQR: 6.313 years, maximum 16.2 years), 212 patients had a CVE (174 MACEs); and 264 patients died, 131 from cardiovascular diseases. One-hundred and sixty-one newly-developed or worsened diabetic retinopathy, 206 achieved the renal composite outcome (127 newly developed microalbuminuria and 104 deteriorated renal function), and 179 newly-developed or worsened peripheral neuropathy. Table 1 (bottom) shows the incidence rates of endpoints in participants divided into tertiles of the NLR. Individuals in the top tertile subgroup had higher incidences of total CVEs, MACEs, and of all-cause and cardiovascular mortality than those in the lower tertiles. There was no difference in the incidence of any microvascular outcome among tertiles of NLR. Kaplan-Meier curves of cumulative incidence of events over time according to tertiles of NLR (Fig. 1) confirmed the increased incidence of these outcomes in the highest tertile in relation to the middle and lowest tertile subgroups.

\section{Risks associated with hematological parameters for incident macrovascular complications and mortality} Tables 2 (analyses with continuous variables) and 3 (analyses with variables categorized into tertiles) present the adjusted risks of hematological parameters for occurrence of cardiovascular complications and mortality. In multivariate-adjusted analyses of 
Table 3 Results of Cox survival analyses for the excess risks associated with hematological parameters, divided into tertiles, for the occurrence of future cardiovascular complications and all-cause mortality

\begin{tabular}{|c|c|c|c|c|}
\hline $\begin{array}{l}\text { Outcomes } \\
\text { Hematological parameters }\end{array}$ & $\begin{array}{l}\text { Model } 1 \\
\text { HR }(95 \% \mathrm{Cl})\end{array}$ & $\begin{array}{l}\text { Model } 2 \\
\text { HR }(95 \% \mathrm{Cl})\end{array}$ & $\begin{array}{l}\text { C-statistic } \\
\text { (AUC) }\end{array}$ & $\begin{array}{l}\text { Relative IDI }{ }^{\mathrm{a}} \\
\text { (\%) }\end{array}$ \\
\hline Total CV events $(n=212)$ & & & $0.725(0.684-0.765)$ & \\
\hline Haemoglobin & $0.79(0.55-1.15)$ & $0.88(0.61-1.29)$ & - & - \\
\hline RDW & $1.06(0.75-1.48)$ & $1.07(0.76-1.52)$ & - & - \\
\hline Leukocytes & $1.16(0.83-1.63)$ & $0.90(0.63-1.27)$ & - & - \\
\hline Neutrophyls & $1.26(0.89-1.76)$ & $1.08(0.76-1.53)$ & - & - \\
\hline Lymphocytes & $0.80(0.58-1.13)$ & $0.66(0.46-0.94) \neq$ & $0.728 \S$ & $4.6 \% \S$ \\
\hline Monocytes & $1.17(0.83-1.63)$ & $0.93(0.66-1.33)$ & - & - \\
\hline Platelets & $1.16(0.82-1.66)$ & $1.12(0.78-1.60)$ & - & - \\
\hline Neutrophyl-to-lymphocyte ratio & $1.55(1.11-2.16) \dagger$ & $1.47(1.04-2.07) \neq$ & $0.729 \S$ & $5.4 \% \S$ \\
\hline Lymphocyte-to-monocyte ratio & $0.79(0.55-1.13)$ & $0.87(0.60-1.26)$ & - & - \\
\hline Platelet-to-lymphocyte ratio & $1.44(1.03-2.01) \ddagger$ & $1.50(1.06-2.12) \neq$ & $0.729 \S$ & $4.6 \% \S$ \\
\hline Monocyte-to-HDL ratio & $1.31(0.93-1.83)$ & $1.04(0.72-1.50)$ & - & - \\
\hline Major CV events $(n=174)$ & & & $0.716(0.673-0.760)$ & \\
\hline Haemoglobin & $0.74(0.49-1.10)$ & $0.75(0.50-1.14)$ & - & - \\
\hline RDW & $1.07(0.74-1.55)$ & $1.10(0.76-1.61)$ & - & - \\
\hline Leukocytes & $1.30(0.89-1.90)$ & $1.02(0.69-1.52)$ & - & - \\
\hline Neutrophyls & $1.24(0.85-1.80)$ & $1.08(0.74-1.59)$ & - & - \\
\hline Lymphocytes & $0.88(0.60-1.27)$ & $0.74(0.50-1.10)$ & - & - \\
\hline Monocytes & $1.21(0.83-1.76)$ & $0.96(0.64-1.43)$ & - & - \\
\hline Platelets & $1.23(0.83-1.82)$ & $1.23(0.83-1.83)$ & - & - \\
\hline Neutrophyl-to-lymphocyte ratio & $1.32(0.93-1.88)$ & $1.21(0.84-1.75)$ & - & - \\
\hline Lymphocyte-to-monocyte ratio & $0.82(0.56-1.20)$ & $0.90(0.61-1.34)$ & - & - \\
\hline Platelet-to-lymphocyte ratio & $1.40(0.97-2.02)$ & $1.48(1.01-2.16) \neq$ & $0.721 \S$ & $6.2 \% \S$ \\
\hline Monocyte-to-HDL ratio & $1.45(0.99-2.11)$ & $1.15(0.76-1.75)$ & - & - \\
\hline CV mortality $(n=131)$ & & & $0.716(0.668-0.765)$ & \\
\hline Haemoglobin & $0.83(0.52-1.32)$ & $0.85(0.52-1.37)$ & - & - \\
\hline RDW & $1.43(0.91-2.22)$ & $1.45(0.92-2.27)$ & - & - \\
\hline Leukocytes & $1.24(0.80-1.91)$ & $0.99(0.63-1.54)$ & - & - \\
\hline Neutrophyls & $1.25(0.81-1.92)$ & $1.11(0.71-1.72)$ & - & - \\
\hline Lymphocytes & $0.77(0.50-1.18)$ & $0.63(0.40-0.99) \neq$ & $0.719 \S$ & $4.1 \% \S$ \\
\hline Monocytes & $1.20(0.78-1.85)$ & $0.94(0.59-1.48)$ & - & - \\
\hline Platelets & $0.93(0.58-1.48)$ & $0.90(0.56-1.44)$ & - & - \\
\hline Neutrophyl-to-lymphocyte ratio & $1.39(0.93-2.07)$ & $1.33(0.88-2.02)$ & - & - \\
\hline Lymphocyte-to-monocyte ratio & $0.60(0.38-0.95) \neq$ & $0.62(0.39-1.00)$ & - & - \\
\hline Platelet-to-lymphocyte ratio & $1.53(0.99-2.35)$ & $1.64(1.06-2.56) \neq$ & $0.723 \S$ & $8.2 \% \S$ \\
\hline Monocyte-to-HDL ratio & $1.56(1.00-2.44) \neq$ & $1.22(0.75-1.98)$ & - & - \\
\hline All-cause mortality $(n=264)$ & & & $0.755(0.717-0.793)$ & \\
\hline Haemoglobin & $0.70(0.50-0.98) \neq$ & $0.76(0.54-1.07)$ & - & - \\
\hline RDW & $1.10(0.82-1.49)$ & $1.09(0.80-1.48)$ & - & - \\
\hline Leukocytes & $1.18(0.87-1.60)$ & $1.00(0.73-1.36)$ & - & - \\
\hline Neutrophyls & $1.17(0.86-1.60)$ & $1.08(0.79-1.48)$ & - & - \\
\hline Lymphocytes & $0.66(0.49-0.90) \dagger$ & $0.58(0.42-0.80)^{*}$ & $0.758 \S$ & $2.6 \% \S$ \\
\hline Monocytes & $1.37(1.01-1.86) \neq$ & $1.15(0.83-1.58)$ & - & - \\
\hline Platelets & $1.11(0.80-1.52)$ & $1.08(0.79-1.50)$ & - & - \\
\hline Neutrophyl-to-lymphocyte ratio & $1.45(1.08-1.96) \neq$ & $1.36(1.00-1.85) \neq$ & $0.756 \S$ & $0.5 \% \S$ \\
\hline Lymphocyte-to-monocyte ratio & $0.56(0.40-0.76)^{*}$ & $0.59(0.43-0.83) \dagger$ & $0.759 \S$ & $5.3 \% \S$ \\
\hline Platelet-to-lymphocyte ratio & $1.39(1.03-1.87) \neq$ & $1.43(1.05-1.94) \ddagger$ & $0.756 \S$ & $0.5 \% \S$ \\
\hline Monocyte-to-HDL ratio & $1.48(1.09-2.01) \neq$ & $1.20(0.86-1.68)$ & - & - \\
\hline
\end{tabular}


Table 3 (continued)

Values are hazard ratios of the highest tertile subgroup in relation to the lowest one and their $95 \%$ confidence intervals; ${ }^{*} p<0.001 ;+p<0.01 ; \neq p<0.05$

The cut-off values of tertiles of each hematological parameter are the following: haemoglobin 13.0 and $14.2 \mathrm{~g} / \mathrm{dl} ; \mathrm{RDW} 12.5$ and $13.5 \%$; leucocytes 6.3 and $8.1 \times 10^{3}$ cells $/ \mathrm{mm}^{3}$; neutrophyls 3.5 and $4.7 \times 10^{3}$ cells $/ \mathrm{mm}^{3}$; lymphocytes 1.8 and $2.5 \times 10^{3}$ cells $/ \mathrm{mm}^{3}$; monocytes 407 and 552 cells $/ \mathrm{mm}^{3} ;$ platelets 210 and $268 \times 10^{3}$ cells/ $\mathrm{mm}^{3}$; neutrophyl-to-lymphocyte ratio 1.56 and 2.22; lymphocyte-to-monocyte ratio 3.94 and 5.35; platelet-to-lymphocyte ratio 95.68 and 129.78 ; monocyte-to-HDL ratio 9.37 and 13.83

Model 1 was adjusted for age and sex

Model 2 was adjusted for age, sex, diabetes duration, BMI, smoking, physical activity, office systolic BP, number and classes of anti-hypertensive drugs in use, presence of micro- and macrovascular complications at baseline, baseline $\mathrm{HbA}_{1 \mathrm{c}}$ and LDL-cholesterol, and use of insulin, statins and aspirin

$H R$ hazard ratio, $\mathrm{Cl}$ confidence interval, $C V$ cardiovascular, $R D W$ red cell distribution width

${ }^{\text {a }} \mathrm{C}$-statistics and relative IDIs were calculated only in case the parameter was significantly associated with the outcome in Model 2 , which was the reference model without the hematological parameter.§ None of the C-statistics were significantly higher than that of the baseline model, as well as no relative IDI was statistically significant

continuous variables (Table 2), no parameter predicted cardiovascular outcomes, except cardiovascular mortality (monocytes count, and neutrophyl-to-lymphocyte, lymphocyte-to-monocyte, and monocyte-to-HDL ratios). However, none of them improved risk discrimination, as assessed by C-statistics increase or IDI index. The highest relative IDI was a statistically-borderline $(0.10<$ p-value $>0.05) \quad 15.5 \%$ improvement obtained by adding either monocytes or monocyte-to-HDL ratio to the baseline risk model. For all-cause mortality, the lymphocytes count and all the 3 ratios with lymphocytes predicted the outcome, but again none of them improved risk discrimination. In multivariate-adjusted categorical analyses (Table 3), individuals in the highest tertile subgroup of lymphocytes count had significantly lower risks of total cardiovascular events and mortality, and those in the highest tertile of neutrophyl-to-lymphocyte and platelet-to-lymphocyte ratios had higher risks of cardiovascular complications and mortality than those in the lowest tertile subgroup. However, none of them was able to improve risk discrimination for any of the outcomes. In categorical analyses, the highest relative IDI was a non-significant $8.2 \%$ improvement for cardiovascular mortality obtained by adding the platelet-to-lymphocyte ratio.

\section{Risks associated with hematological parameters for incident microvascular complications}

Tables 4 (with continuous variables) and 5 (with variables categorized into tertiles) present the adjusted risks of hematological parameters for occurrence of microvascular complications. In general, no hematological parameter was predictive of any microvascular outcome. The exceptions were the hemoglobin concentration (as a continuous variable) for retinopathy outcome, and the lymphocyte-to-monocyte ratio (as a categorical variable) for renal function deterioration. However, none of them significantly improved risk discrimination for these outcomes: hemoglobin increased the C-statistic from 0.750 to 0.752 and the relative IDI demonstrated an improvement of $1.8 \%$ for retinopathy risk discrimination; whereas the categorical lymphocyte-to-monocyte ratio increased the C-statistic from 0.680 to 0.693 and the relative IDI showed a statistically-borderline improvement of $14.3 \%$ for renal failure risk discrimination. The observed association between hemoglobin concentration and the renal function deterioration outcome was probably due to reverse causality.

\section{Discussion \\ Main findings}

We investigated in a cohort of middle-aged type 2 diabetic individuals with a long follow-up, the prognostic importance of several hematological parameters for macro- and microvascular outcomes and mortality. This study has three main findings. First, the hematological parameters were mainly predictors of mortality (all-cause and cardiovascular), but more weakly associated with non-fatal CVEs. Higher lymphocytes count was protective and monocytes count was hazardous, and most leukocyte ratios that included lymphocytes were predictive of cardiovascular and all-cause mortality. Second, no hematological parameter was predictive of microvascular complications, except lower hemoglobin concentration for retinopathy and lower lymphocyte-to-monocyte ratio for renal function deterioration. Third, no hematological parameter was able to significantly improve risk discrimination for any outcome. The highest observed relative IDIs were a statistically-borderline $15.5 \%$ improvement of monocytes count and monocyte-to-HDL ratio for cardiovascular mortality, and a $14.3 \%$ improvement of lymphocyte-to-monocyte ratio for renal failure outcome. Although hematological parameters are easily measurable in routine laboratory exams, they did not appear to add significant prognostic information beyond traditional risk factors in individuals with type 2 diabetes. 
Table 4 Results of Cox survival analyses for the excess risks associated with continuous hematologic parameters (increments of 1-SD) for the occurrence of future microvascular complications

\begin{tabular}{|c|c|c|}
\hline $\begin{array}{l}\text { Outcomes } \\
\text { Hematologic parameters }\end{array}$ & $\begin{array}{l}\text { Model } 1 \\
\text { HR ( } 95 \% \mathrm{Cl})\end{array}$ & $\begin{array}{l}\text { Model } 2 \\
\text { HR }(95 \% \mathrm{Cl})\end{array}$ \\
\hline \multicolumn{3}{|l|}{ Retinopathy $(n=161)$} \\
\hline Haemoglobin & $0.76(0.64-0.90)+$ & $0.79(0.66-0.95) \neq$ \\
\hline RDW & $1.12(0.97-1.29)$ & $1.15(0.99-1.35)$ \\
\hline Leukocytes & $1.13(0.97-1.32)$ & $1.14(0.97-1.33)$ \\
\hline Neutrophyls & $1.06(0.91-1.25)$ & $1.08(0.92-1.26)$ \\
\hline Lymphocytes & $1.10(0.92-1.31)$ & $1.16(0.97-1.38)$ \\
\hline Monocytes & $1.05(0.91-1.23)$ & $1.00(0.85-1.18)$ \\
\hline Platelets & $1.08(0.91-1.28)$ & $1.08(0.92-1.27)$ \\
\hline Neutrophyl-to-lymphocyte ratio & $1.02(0.87-1.21)$ & $0.98(0.84-1.14)$ \\
\hline Lymphocyte-to-monocyte ratio & $0.98(0.83-1.16)$ & $1.08(0.91-1.28)$ \\
\hline Platelet-to-lymphocyte ratio & $0.95(0.81-1.11)$ & $0.91(0.77-1.08)$ \\
\hline Monocyte-to-HDL ratio & $1.06(0.91-1.23)$ & $1.01(0.85-1.20)$ \\
\hline \multicolumn{3}{|l|}{ Renal composite $(n=206)$} \\
\hline Haemoglobin & $0.87(0.74-1.01)$ & $0.87(0.74-1.02)$ \\
\hline RDW & $1.02(0.89-1.17)$ & $1.01(0.88-1.17)$ \\
\hline Leukocytes & $1.16(1.01-1.33) \neq$ & $1.12(0.97-1.29)$ \\
\hline Neutrophyls & $1.15(1.00-1.32) \neq$ & $1.11(0.97-1.28)$ \\
\hline Lymphocytes & $0.98(0.84-1.16)$ & $0.99(0.84-1.17)$ \\
\hline Monocytes & $1.14(1.00-1.30)$ & $1.11(0.96-1.27)$ \\
\hline Platelets & $1.05(0.91-1.21)$ & $1.06(0.92-1.23)$ \\
\hline Neutrophyl-to-lymphocyte ratio & $1.11(0.97-1.26)$ & $1.07(0.94-1.23)$ \\
\hline Lymphocyte-to-monocyte ratio & $0.90(0.77-1.06)$ & $0.95(0.81-1.11)$ \\
\hline Platelet-to-lymphocyte ratio & $0.99(0.86-1.14)$ & $1.00(0.86-1.15)$ \\
\hline Monocyte-to-HDL ratio & $1.15(1.01-1.32) \neq$ & $1.11(0.96-1.29)$ \\
\hline \multicolumn{3}{|l|}{ Microalbuminuria $(n=127)$} \\
\hline Haemoglobin & $0.89(0.74-1.08)$ & $0.88(0.72-1.07)$ \\
\hline RDW & $1.01(0.84-1.22)$ & $1.02(0.85-1.23)$ \\
\hline Leukocytes & $1.16(0.98-1.39)$ & $1.15(0.96-1.38)$ \\
\hline Neutrophyls & $1.18(0.99-1.41)$ & $1.16(0.97-1.40)$ \\
\hline Lymphocytes & $0.99(0.80-1.22)$ & $1.02(0.82-1.26)$ \\
\hline Monocytes & $1.11(0.94-1.31)$ & $1.10(0.92-1.30)$ \\
\hline Platelets & $1.03(0.86-1.23)$ & $1.03(0.86-1.24)$ \\
\hline Neutrophyl-to-lymphocyte ratio & $1.10(0.93-1.30)$ & $1.07(0.90-1.28)$ \\
\hline Lymphocyte-to-monocyte ratio & $0.90(0.74-1.10)$ & $0.93(0.76-1.14)$ \\
\hline Platelet-to-lymphocyte ratio & $0.97(0.81-1.16)$ & $0.95(0.79-1.14)$ \\
\hline Monocyte-to-HDL ratio & $1.11(0.93-1.32)$ & $1.10(0.91-1.32)$ \\
\hline \multicolumn{3}{|l|}{ Renal failure $(n=104)$} \\
\hline Haemoglobin & $0.75(0.61-0.93) \dagger$ & $0.79(0.64-0.99) \neq$ \\
\hline RDW & $1.07(0.89-1.29)$ & $1.06(0.88-1.28)$ \\
\hline Leukocytes & $1.15(0.94-1.41)$ & $1.09(0.89-1.34)$ \\
\hline Neutrophyls & $1.15(0.95-1.40)$ & $1.11(0.92-1.35)$ \\
\hline Lymphocytes & $0.94(0.75-1.19)$ & $0.93(0.73-1.19)$ \\
\hline Monocytes & 1.24 (1.03-1.49)‡ & $1.19(0.97-1.45)$ \\
\hline Platelets & $1.03(0.84-1.28)$ & $1.04(0.85-1.27)$ \\
\hline Neutrophyl-to-lymphocyte ratio & $1.15(0.96-1.38)$ & $1.11(0.92-1.33)$ \\
\hline Lymphocyte-to-monocyte ratio & $0.82(0.64-1.04)$ & $0.86(0.67-1.11)$ \\
\hline Platelet-to-lymphocyte ratio & $1.01(0.83-1.23)$ & $1.02(0.84-1.24)$ \\
\hline
\end{tabular}

Table 4 (continued)

\begin{tabular}{lll}
\hline $\begin{array}{l}\text { Outcomes } \\
\text { Hematologic parameters }\end{array}$ & $\begin{array}{l}\text { Model 1 } \\
\text { HR (95\% Cl) }\end{array}$ & $\begin{array}{l}\text { Model 2 } \\
\text { HR (95\% Cl) }\end{array}$ \\
\hline $\begin{array}{l}\text { Monocyte-to-HDL ratio } \\
\text { Peripheral neuropathy }(\mathrm{n}=179)\end{array}$ & $1.17(0.97-1.43)$ & $1.09(0.88-1.35)$ \\
Haemoglobin & $0.87(0.71-1.06)$ & $1.19(0.93-1.52)$ \\
RDW & $1.11(0.92-1.35)$ & $0.85(0.67-1.08)$ \\
Leukocytes & $1.16(0.96-1.40)$ & $1.10(0.89-1.37)$ \\
Neutrophyls & $1.19(0.99-1.44)$ & $1.13(0.90-1.40)$ \\
Lymphocytes & $0.91(0.73-1.14)$ & $0.93(0.72-1.20)$ \\
Monocytes & $1.00(0.83-1.21)$ & $0.99(0.80-1.23)$ \\
Platelets & $0.95(0.78-1.16)$ & $0.93(0.74-1.17)$ \\
Neutrophyl-to-lymphocyte ratio & $1.23(1.02-1.49) \neq$ & $1.16(0.92-1.45)$ \\
Lymphocyte-to-monocyte ratio & $0.90(0.74-1.09)$ & $0.90(0.72-1.12)$ \\
Platelet-to-lymphocyte ratio & $1.04(0.86-1.26)$ & $1.00(0.80-1.25)$ \\
Monocyte-to-HDL ratio & $1.05(0.86-1.28)$ & $1.09(0.86-1.38)$
\end{tabular}

Values are hazard ratios and $95 \%$ confidence intervals estimated by Cox analyses for a 1-SD increment in each hematologic parameter; except for peripheral neuropathy endpoint, which is odds ratios and $95 \%$ confidence intervals estimated by logistic regressions; $t p<0.01 ; \neq p<0.05$. The SDs of the hematologic parameters were shown on Table 1

Model 1 adjusted for age and sex

Model 2 was adjusted for age, sex, diabetes duration, BMI, smoking, physical activity, office systolic BP, number and classes of anti-hypertensive drugs in use, presence of micro- and macrovascular complications at baseline, baseline $\mathrm{HbA}_{1 \mathrm{c}}$ and LDL-cholesterol, and use of insulin, statins and aspirin; except for peripheral neuropathy where BMI was substituted by body height and further adjusted for the time interval between baseline and follow-up neuropathy examinations $H R$ hazard ratio, $\mathrm{Cl}$ confidence interval, $R D W$ red cell distribution width, $S D$ standard deviation

\section{Previous studies on hematologic parameters}

As far as we know, there were only 2 previous longitudinal studies that evaluated hematological parameters for adverse outcomes in individuals with diabetes [11, $22,23]$. The first one $[11,22]$ retrospectively evaluated 338 patients with diabetes and reported that higher NLR was associated with increased odds of developing renal function deterioration (a decrease in eGFR $>12 \mathrm{ml} / \mathrm{min}$ to a value $<60 \mathrm{ml} / \mathrm{min}$ ) over a 3 -year period [22], and with higher risks of having a CVE or death over a 4-year period [11]. The second study [23] prospectively followed-up 880 individuals with diabetes over a median of 3.9 years, and reported that higher monocytes count was associated with higher risk of all-cause mortality, which was mainly evident in those with pre-existent macrovascular complications. Our prospective study over a longer follow-up confirmed these initial observations and expanded them by evaluating a larger set of hematological parameters and a comprehensive number of micro- and macrovascular complications outcomes. We demonstrated that, when examined separately, the lymphocytes count was in general the best predictive blood cell count parameter, but the monocytes count was better to predict cardiovascular mortality. The predictive 
Table 5 Results of Cox survival analyses for the excess risks associated with hematologic parameters, divided into tertiles, for the occurrence of future microvascular complications

\begin{tabular}{|c|c|c|}
\hline $\begin{array}{l}\text { Outcomes } \\
\text { Hematologic parameters }\end{array}$ & $\begin{array}{l}\text { Model } 1 \\
\text { HR }(95 \% \mathrm{Cl})\end{array}$ & $\begin{array}{l}\text { Model } 2 \\
\text { HR }(95 \% \mathrm{Cl})\end{array}$ \\
\hline \multicolumn{3}{|l|}{ Rethinopathy $(n=161)$} \\
\hline Haemoglobin & $0.57(0.38-0.86) \dagger$ & $0.65(0.42-1.00)$ \\
\hline RDW & $1.40(0.95-2.07)$ & $1.49(1.00-2.22)$ \\
\hline Leukocytes & $1.33(0.90-1.96)$ & $1.46(0.97-2.19)$ \\
\hline Neutrophyls & $1.03(0.71-1.50)$ & $1.23(0.83-1.82)$ \\
\hline Lymphocytes & $1.20(0.80-1.78)$ & $1.34(0.89-2.02)$ \\
\hline Monocytes & $1.19(0.81-1.75)$ & $1.20(0.80-1.80)$ \\
\hline Platelets & $1.00(0.68-1.48)$ & $1.07(0.72-1.60)$ \\
\hline Neutrophyl-to-lymphocyte ratio & $0.97(0.66-1.43)$ & $0.97(0.65-1.43)$ \\
\hline Lymphocyte-to-monocyte ratio & $1.01(0.68-1.49)$ & $1.18(0.78-1.76)$ \\
\hline Platelet-to-lymphocyte ratio & $0.93(0.63-1.36)$ & $0.84(0.57-1.24)$ \\
\hline Monocyte-to-HDL ratio & $1.40(0.97-2.02)$ & $1.38(0.91-2.09)$ \\
\hline \multicolumn{3}{|l|}{ Renal composite $(n=206)$} \\
\hline Haemoglobin & $0.67(0.46-0.98) \neq$ & $0.67(0.45-0.98) \neq$ \\
\hline RDW & $1.13(0.80-1.58)$ & $1.10(0.78-1.55)$ \\
\hline Leukocytes & $1.47(1.04-2.09) \ddagger$ & $1.38(0.97-1.98)$ \\
\hline Neutrophyls & $1.25(0.90-1.74)$ & $1.19(0.85-1.67)$ \\
\hline Lymphocytes & $1.14(0.81-1.61)$ & $1.18(0.82-1.69)$ \\
\hline Monocytes & $1.18(0.84-1.66)$ & $1.10(0.77-1.57)$ \\
\hline Platelets & $1.02(0.71-1.47)$ & $1.06(0.74-1.53)$ \\
\hline Neutrophyl-to-lymphocyte ratio & $1.23(0.88-1.71)$ & $1.13(0.80-1.59)$ \\
\hline Lymphocyte-to-monocyte ratio & $0.75(0.52-1.07)$ & $0.78(0.54-1.13)$ \\
\hline Platelet-to-lymphocyte ratio & $1.04(0.74-1.45)$ & $1.04(0.74-1.47)$ \\
\hline Monocyte-to-HDL ratio & $1.17(0.84-1.64)$ & $1.04(0.73-1.49)$ \\
\hline \multicolumn{3}{|l|}{ Microalbuminuria $(n=127)$} \\
\hline Haemoglobin & $0.70(0.43-1.13)$ & $0.65(0.40-1.07)$ \\
\hline RDW & $1.20(0.77-1.86)$ & $1.22(0.78-1.91)$ \\
\hline Leukocytes & $1.55(0.99-2.43)$ & $1.49(0.95-2.35)$ \\
\hline Neutrophyls & $1.43(0.94-2.18)$ & $1.36(0.88-2.09)$ \\
\hline Lymphocytes & $1.09(0.71-1.69)$ & $1.17(0.74-1.84)$ \\
\hline Monocytes & $1.01(0.66-1.54)$ & $0.99(0.64-1.53)$ \\
\hline Platelets & $1.24(0.77-1.99)$ & $1.22(0.75-1.97)$ \\
\hline Neutrophyl-to-lymphocyte ratio & $1.23(0.81-1.86)$ & $1.12(0.73-1.72)$ \\
\hline Lymphocyte-to-monocyte ratio & $0.77(0.48-1.21)$ & $0.80(0.50-1.28)$ \\
\hline Platelet-to-lymphocyte ratio & $1.02(0.66-1.58)$ & $0.97(0.62-1.51)$ \\
\hline Monocyte-to-HDL ratio & $1.00(0.64-1.55)$ & $0.95(0.60-1.51)$ \\
\hline \multicolumn{3}{|l|}{ Renal failure $(n=104)$} \\
\hline Haemoglobin & $0.50(0.29-0.87) \neq$ & $0.58(0.33-1.01)$ \\
\hline RDW & $1.13(0.69-1.83)$ & $1.10(0.68-1.80)$ \\
\hline Leukocytes & $1.35(0.83-2.18)$ & $1.19(0.73-1.95)$ \\
\hline Neutrophyls & $1.17(0.74-1.86)$ & $1.11(0.69-1.78)$ \\
\hline Lymphocytes & $1.10(0.68-1.78)$ & $1.03(0.62-1.71)$ \\
\hline Monocytes & $1.67(1.01-2.74) \neq$ & $1.50(0.89-2.53)$ \\
\hline Platelets & $0.82(0.50-1.35)$ & $0.87(0.53-1.45)$ \\
\hline Neutrophyl-to-lymphocyte ratio & $1.54(0.95-2.47)$ & $1.47(0.90-2.41)$ \\
\hline Lymphocyte-to-monocyte ratio & $0.56(0.33-0.93) \neq$ & $0.58(0.34-0.99) \neq$ \\
\hline Platelet-to-lymphocyte ratio & $1.13(0.72-1.79)$ & $1.17(0.73-1.88)$ \\
\hline
\end{tabular}

Table 5 (continued)

\begin{tabular}{lll}
\hline $\begin{array}{l}\text { Outcomes } \\
\text { Hematologic parameters }\end{array}$ & $\begin{array}{l}\text { Model 1 } \\
\text { HR (95\% Cl) }\end{array}$ & $\begin{array}{l}\text { Model 2 } \\
\text { HR (95\% Cl) }\end{array}$ \\
\hline $\begin{array}{l}\text { Monocyte-to-HDL ratio } \\
\text { Peripheral neuropathy }(\mathrm{n}=179)\end{array}$ & $1.30(0.82-2.07)$ & $1.09(0.66-1.81)$ \\
Haemoglobin & $0.70(0.43-1.14)$ & $1.45(0.80-2.64)$ \\
RDW & $1.56(0.98-2.48)$ & $0.69(0.39-1.21)$ \\
Leukocytes & $1.41(0.89-2.22)$ & $1.35(0.80-2.28)$ \\
Neutrophyls & $1.33(0.84-2.10)$ & $1.33(0.78-2.24)$ \\
Lymphocytes & $0.77(0.48-1.23)$ & $0.79(0.46-1.35)$ \\
Monocytes & $1.02(0.65-1.61)$ & $0.98(0.58-1.66)$ \\
Platelets & $0.92(0.57-1.48)$ & $0.90(0.52-1.56)$ \\
Neutrophyl-to-lymphocyte ratio & $1.54(0.97-2.46)$ & $1.35(0.79-2.31)$ \\
Lymphocyte-to-monocyte ratio & $0.76(0.47-1.23)$ & $0.75(0.43-1.30)$ \\
Platelet-to-lymphocyte ratio & $0.90(0.57-1.41)$ & $0.92(0.54-1.54)$ \\
Monocyte-to-HDL ratio & $1.24(0.79-1.95)$ & $1.41(0.82-2.43)$
\end{tabular}

Values are hazard ratios of the highest tertile subgroup in relation to the lowest one and their $95 \%$ confidence intervals estimated by Cox analyses; except for peripheral neuropathy endpoint, which are odds ratios and their $95 \%$ confidence intervals estimated by logistic regressions. $t p<0.01 ; \neq p<0.05$. The cut-off values of tertiles of each hematologic parameter were shown on Table 3 Model 1 adjusted for age and sex

Model 2 was adjusted for age, sex, diabetes duration, BMI, smoking, physical activity, office systolic BP, number and classes of anti-hypertensive drugs in use, presence of micro- and macrovascular complications at baseline, baseline $\mathrm{HbA}_{1 \mathrm{c}}$ and LDL-cholesterol, and use of insulin, statins and aspirin; except for peripheral neuropathy where BMI was substituted by body height and further adjusted for the time interval between baseline and follow-up neuropathy examinations $H R$ hazard ratio, $\mathrm{Cl}$ confidence interval, $R D W$ red cell distribution width

performance of the several white blood cell ratios analyzed appeared to depend basically on the lymphocytes/ monocytes count. Total leukocytes, neutrophyls and platelets counts were not predictive of any of the outcomes in isolation; and serum hemoglobin concentration, but not the RDW, was only predictive of retinopathy development/worsening.

Relatively few studies evaluated low absolute lymphocytes count as a prognostic marker [16, 34-37]; three were in patients with cardiovascular diseases [34-36], two in population-based samples [16, 37] and none of them in individuals with diabetes. An observational cohort study showed that low lymphocytes were predictive of all-cause and several cause-specific mortality, including cardiovascular one [37]. The other populationbased retrospective study showed that lymphopenia was associated with increased all-cause mortality risk, which was particularly evident in individuals with elevated C-reactive protein and/or RDW [16], a parameter of bone marrow dysregulation that may reflect chronic inflammation [38]. Another investigation performed in a retrospective database of patients who were referred to coronary angiography also demonstrated low lymphocytes count as a predictor of mortality, and the 
association with higher RDW improved its predictive capacity [37]. In accordance with these studies, we demonstrated in a type 2 diabetes population that low lymphocyte count was a predictor of cardiovascular and all-cause mortalities, and additionally we also showed that low lymphocyte count was a predictor of total CVEs. We may speculate on the reasons why lymphopenia was an independent risk factor for mortality in individuals of different clinical settings. This might be due to a decreased immune vigilance that makes them less capable of surviving to severe disease. As well, reduced lymphocytes could be an indicator of general frailty that confers and an increased risk of any cause of death. Indeed, older age is associated with reduced lymphocytes count [39] that may compromise global immune capacity. Reduced lymphocytes might also indicate chronic inflammatory, metabolic or neuro-endocrine stress factors and thus be associated with reduced survival as an epiphenomenon [16].

\section{Strengths and limitations}

The study has some limitations that shall be noticed. First, it is a prospective observational cohort; hence no causal relationships, nor physiopathological inferences, can be made, but only speculated. Moreover, as with any cohort study, residual confounding due to unmeasured or unknown factors cannot be ruled out. Second, it enrolled mainly middle-aged to elderly individuals with long-standing type 2 diabetes followed-up in a tertiarycare university hospital. Hence, our results might not be generalized to younger individuals with recent onset type 2 diabetes or at primary care management. Otherwise, this study main strength is its well-documented cohort of individuals with type 2 diabetes under standardized care and annual outcomes evaluation over a long 10-year follow-up, which allowed a comprehensive analysis of the excess risks associated with several hematological parameters for separate micro- and macrovascular complications and mortality. And also all individuals who had low or high total leucocytes count had their exam repeated after a month to confirm the results, hence preventing falsely spurious values.

\section{Conclusions}

This prospective long-term cohort study demonstrated that low lymphocytes and high monocytes counts and the leucocytes ratios that mainly included lymphocytes were predictors of cardiovascular events and cardiovascular and all-cause mortalities, and possibly also of renal function deterioration, in individuals with type 2 diabetes. However, their inclusion in the models did not improve risk stratification beyond traditional risk factors. Overall, hematological parameters appeared to add only modest prognostic information in type 2 diabetes.

\section{Abbreviations}

CVE: Cardiovascular event; SBP: Systolic blood pressure; IDI: Integrated discrimination improvement; MACE: Major adverse cardiovascular events; MI: Myocardial infarction; SBP: Systolic blood pressure; NLR: Neutrophyl-tolymphocyte ratio; RDW: Red blood cell distribution width.

\section{Acknowledgements}

Not applicable.

\section{Authors' contributions}

CRLC, NCL and GFS conceived and designed the study, followed-up the patients and obtained the data. CRLC drafted the manuscript. GFS analyzed the data and is the guarantor. All authors helped interpret the results and reviewed the manuscript. GFS had full access to all of the data and takes responsibility for the integrity of the data and the accuracy of data analysis. All authors read and approved the final manuscript.

\section{Funding}

This study was supported by grants 304069/2019-1 and 303492/2019-8 from the Conselho Nacional de Desenvolvimento Científico e Tecnológico (CNPq, Brazil) and by Grants E-26/202.807/2017 and E-26/202.535/2019 from the Fundação Carlos Chagas Filho de Amparo a Pesquisa do Estado do Rio de Janeiro (FAPERJ, Brazil). The sponsors have no role in study design, data collection and analysis, results interpretation or in preparation, review and approval of the manuscript.

\section{Availability of data and materials}

The Rio de Janeiro Type 2 Diabetes Cohort Study is an on-going study, and its dataset is not publicly available due to individual privacy of the participants. However, it may be available from the corresponding author on reasonable request.

\section{Declarations}

\section{Ethics approval and consent to participate}

The study was approved by the Research Ethics Committee of School of Medicine and University Hospital, Federal University of Rio de Janeiro (Number 124/2004), and all participants gave written informed consent.

Consent for publication

Not applicable.

\section{Competing interests}

The authors declare that they have no competing interests.

Received: 2 June 2021 Accepted: 23 June 2021

Published online: 06 July 2021

References

1. Poznyak A, Grechko AV, Poggio P, Myasoedova VA, Alfieri V, Orekhov AN. The diabetes mellitus-atherosclerosis connection: the role of lipid and glucose metabolism and chronic inflammation. Int J Mol Sci. 2020;21:1835.

2. Fujita T, Hemmi S, Kajiwara M, Yabuki M, Fuke Y, Satomura A, Soma M. Complement-mediated chronic inflammation is associated with diabetic microvascular complication. Diabetes Metab Res Rev. 2013;29:220-6.

3. Li X, Shen J, Lu Z, Chen M, Fang X, Wang G. High neutrophil-to-lymphocyte ratio is associated with increased carotid artery intima-media thickness in type 2 diabetes. J Diabetes Investig. 2017;8:101-7.

4. Tang J, Kern TS. Inflammation in diabetic retinopathy. Prog Retin Eye Res. 2011;30:343-58. 
5. Semeraro F, Cancarini A, dell'Omo R, Rezzola S, Romano MR, Costagliola C. Diabetic retinopathy: vascular and inflammatory disease. J Diabetes Res. 2015;2015:582060.

6. Wan H, Cai Y, Wang Y, Fang S, Chen C, Chen Y, et al. The unique association between the level of peripheral blood monocytes and the prevalence of diabetic retinopathy: a cross-sectional study. J Transl Med. 2020;18:248.

7. Liu S, Zheng H, Zhu X, Mao F, Zhang S, Shi H, et al. Neutrophil-to-lymphocyte ratio is associated with diabetic peripheral neuropathy in type 2 diabetes patients. Diabetes Res Clin Pract. 2017;130:90-7.

8. Wan H, Wang Y, Fang S, Chen Y, Zhang W, Xia F, et al. Associations between the neutrophil-to-lymphocyte ratio and diabetic complications in adults with diabetes: a cross-sectional study. J Diabetes Res. 2020;2020:6219545.

9. Drechsler M, Doring Y, Megens RT, Soehnlein O. Neutrophilic granulocytes-promiscuous accelerators of atherosclerosis. Thromb Haemost. 2011;106:839-48.

10. Zernecke A, Bot I, Djalali-Talab Y, Shagdarsuren E, Bidzhekov K, Meiler S, et al. Protective role of $C X C$ receptor $4 / C X C$ ligand 12 unveils the importance of neutrophils in atherosclerosis. Circ Res. 2008;102:209-17.

11. Azab B, Chainani V, Shah N, McGinn JT. Neutrophil-lymphocyte ratio as a predictor of major adverse cardiac events among diabetic population: a 4-year follow-up study. Angiology. 2013;64:456-65.

12. Fest J, Ruiter TR, Groot Koerkamp B, Rizopoulos D, Ikram MA, van Eijck $\mathrm{CHJ}$, Stricker BH. The neutrophil-to-lymphocyte ratio is associated with mortality in the general population: the Rotterdam Study. Eur J Epidemiol. 2019;34:463-70.

13. Liu J, Liu X, Li Y, Quan J, Wei S, An S, et al. The association of neutrophil to lymphocyte ratio, mean platelet volume, and platelet distribution width with diabetic retinopathy and nephropathy: a meta-analysis. Biosci Rep. 2018;38:BSR20180172.

14. Verdoia M, Schaffer A, Barbieri L, Aimaretti G, Marino P, Sinigaglia F, Novara Atherosclerosis Study Group (NAS), et al. Impact of diabetes on neutrophil-to-lymphocyte ratio and its relationship to coronary artery disease. Diabetes Metab. 2015;41:304-11.

15. Demirtas L, Degirmenci H, Akbas EM, Ozcicek A, Timuroglu A, Gurel A, Ozcicek F. Association of hematologicalal indicies with diabetes, impaired glucose regulation and microvascular complications of diabetes. Int J Clin Exp Med. 2015;8:11420-7.

16. Zidar DA, Al-Kindi SG, Liu Y, Krieger NI, Perzynski AT, Osnard M, et al. Association of lymphopenia with risk of mortality among adults in the US general population. JAMA Netw Open. 2019;2:e1916526.

17. Wang JR, Chen Z, Yang K, Yang HJ, Tao WY, Li YP, et al. Association between neutrophil-to-lymphocyte ratio, platelet-to-lymphocyte ratio, and diabetic retinopathy among diabetic patients without a related family history. Diabetol Metab Syndr. 2020;12:55.

18. Karatas A, Turkmen E, Erdem E, Dugeroglu H, Kaya Y. Monocyte to highdensity lipoprotein cholesterol ratio in patients with diabetes mellitus and diabetic nephropathy. Biomark Med. 2018;12:953-9.

19. Tonelli M, Wiebe N, James MT, Naugler C, Manns BJ, Klarenbach SW, Hemmelgarn BR. Red cell distribution width associations with clinical outcomes: a population-based cohort study. PLOS ONE. 2019;14:e212374.

20. Rajakariar R, Lawrence T, Bystrom J, Hilliard M, Colville-Nash P, Bellingan $\mathrm{G}$, et al. Novel biphasic role for lymphocytes revealed during resolving inflammation. Blood. 2008;111:4184-92.

21. El Kebir D, Filep JG. Targeting neutrophil apoptosis for enhancing the resolution of inflammation. Cells. 2013:2:330-48.

22. Azab B, Daoud J, Naeem FB, Nasr R, Ross J, Ghimire P, et al. Neutrophil-tolymphocyte ratio as a predictor of worsening renal function in diabetic patients (3-year follow-up study). Ren Fail. 2012;34:571-6.

23. Yang $L$, Hu J, Wang Z, Chen $X$, Wang $Y$, Yang $S$, et al. Peripheral monocyte count is an independent predictor of all-cause mortality in type 2 diabetes with macro-vascular complications. Medicine (Baltimore). 2020;99:e18876.

24. Yue S, Zhang J, Wu J, Teng W, Liu L, Chen L. Use of the monocyte-tolymphocyte ratio to predict diabetic retinopathy. Int J Environ Res Public Health. 2015;12:10009-100019.

25. Salles GF, Leite NC, Pereira BB, Nascimento EM, Cardoso CR. Prognostic impact of clinic and ambulatory blood pressure components in high-risk type 2 diabetic patients: the Rio de Janeiro Type 2 Diabetes Cohort Study. J Hypertens. 2013;31:2176-86.
26. Cardoso CR, Leite NC, Ferreira MT, Salles GF. Prognostic importance of baseline and serial glycated hemoglobin levels in high-risk patients with type 2 diabetes: the Rio de Janeiro Type 2 Diabetes Cohort Study. Acta Diabetol. 2015:52:21-9.

27. Cardoso CR, Moran CB, Marinho FS, Ferreira MT, Salles GF. Increased aortic stiffness predicts future development and progression of peripheral neuropathy in patients with type 2 diabetes: the Rio de Janeiro Type 2 Diabetes Cohort Study. Diabetologia. 2015;58:2161-8.

28. Cardoso CRL, Leite NC, Dib E, Salles GF. Predictors of development and progression of retinopathy in patients with type 2 diabetes: importance of blood pressure parameters. Sci Rep. 2017;7:4867.

29. Cardoso CRL, Leite NC, Salles GC, Ferreira MT, Salles GF. Aortic stiffness and ambulatory blood pressure as predictors of diabetic kidney disease: a competing risks analysis from the Rio de Janeiro Type 2 Diabetes Cohort Study. Diabetologia. 2018;61:455-65.

30. Santos TRM, Melo JV, Leite NC, Salles GF, Cardoso CRL. Usefulness of the vibration perception thresholds measurement as a diagnostic method for diabetic peripheral neuropathy: results from the Rio de Janeiro Type 2 Diabetes cohort study. J Diabetes Complications. 2018;32:770-6.

31. DeLong ER, DeLong DM, Clarke-Pearson DL. Comparing the areas under two or more correlated receiver operating characteristic curves: a nonparametric approach. Biometrics. 1988;44:837-45.

32. Pencina MJ, D'Agostino RB Sr, D'Agostino RB Jr, Vasan RS. Evaluating the added predictive ability of a new marker: from area under the ROC curve to reclassification and beyond. Stat Med. 2008;27:157-72.

33. Pencina MJ, D'Agostino RB Sr, Demler OV. Novel metrics for evaluating improvement in discrimination: net reclassification and integrated discrimination improvement for normal variables and nested models. Stat Med. 2012;31:101-13.

34. Vaduganathan M, Ambrosy AP, Greene SJ, Mentz RJ, Subacius HP, Maggioni AP, EVEREST trial investigators, et al. Predictive value of low relative lymphocyte count in patients hospitalized for heart failure with reduced ejection fraction: insights from the EVEREST trial. Circ Heart Fail. 2012;5:750-8.

35. Berry C, Norrie J, Hogg K, Brett M, Stevenson K, McMurray JJ. The prevalence, nature, and importance of hematological abnormalities in heart failure. Am Heart J. 2006;151:1313-21.

36. Zafrir B, Hussein S, Jaffe R, Barnett-Griness O, Saliba W. Lymphopenia and mortality among patients undergoing coronary angiography: long-term follow-up study. Cardiol J. 2020. https://doi.org/10.5603/CJ. a2020.0141 (Epub ahead of print)

37. Warny M, Helby J, Nordestgaard BG, Birgens H, Bojesen SE. Incidental lymphopenia and mortality: a prospective cohort study. CMAJ. 2020;192:E25-33.

38. Weiss G, Ganz T, Goodnough LT. Anemia of inflammation. Blood. 2019:133:40-5.

39. Rea IM, Stewart M, Campbell P, Alexander HD, Crockard AD, Morris TC. Changes in lymphocyte subsets, interleukin 2, and soluble interleukin 2 receptor in old and very old age. Gerontology. 1996;42:69-78.

\section{Publisher's Note}

Springer Nature remains neutral with regard to jurisdictional claims in published maps and institutional affiliations.

$$
\begin{aligned}
& \text { Ready to submit your research? Choose BMC and benefit from: } \\
& \text { - fast, convenient online submission } \\
& \text { - thorough peer review by experienced researchers in your field } \\
& \text { - rapid publication on acceptance } \\
& \text { - support for research data, including large and complex data types } \\
& \text { - gold Open Access which fosters wider collaboration and increased citations } \\
& \text { - maximum visibility for your research: over } 100 \mathrm{M} \text { website views per year }
\end{aligned}
$$

At $\mathrm{BMC}$, research is always in progress.

Learn more biomedcentral.com/submissions 